\title{
Derivational Complexity in EFL Learners' Development of Bi-clausal Wh-questions
}

\author{
Jung-Tae Kim \\ Incheon National University, Incheon, South Korea
}

\begin{abstract}
This paper aims to investigate Korean learners' interlanguage with respect to the production of English bi-clausal wh-questions. One hundred seven adult Korean-speaking learners of English in three proficiency groups took part in a production task designed to elicit English bi-clausal $w h$-questions. The study specifically asked what interlanguage structures Korean EFL learners would produce and whether the structures would change as learners' English proficiency advances. The results revealed that Korean EFL learners produced a range of alternative bi-clausal structures, including $w h$-scope marking, silent scope marking, $w h$-scope marking with embedded $w h$-in-situ, L1 clause order, and $w h$-about- $w h$ type constructions. Comparison of three proficiency groups showed that as the learners' English proficiency increases, they tend to produce an increasing number of derivationally more complex alternatives. It is argued that derivational complexity plays a role in the developmental process of Korean EFL learners' interlanguage for bi-clausal wh-questions.
\end{abstract}

Index Terms-interlanguage, bi-clausal wh-question, derivational complexity, wh-movement, wh-scope marking

\section{INTRODUCTION}

In English, complex wh-questions have been analyzed as involving long-distance movement of the wh-phrase, as illustrated in (1).

(1) a. $\left[_{\mathrm{CP}} \mathrm{Who}_{i}\right.$ do you think $\left[{ }_{\mathrm{CP}} t_{i}\right.$ Tom loves $\left.t_{i}\right]$ ?

In (1), the wh-phrase that originated in the object position in embedded clause goes through successive cyclic movement before rising to Spec-CP of the main clause. This long-distance movement has been known to pose considerable difficulty for child L1 acquisition and causes children to resort to some alternative options such as ( $2 \mathrm{a}$ ) and (2b) below.

(2) a.* What do you think who Bert kissed?

b.* Who do you think who Gumby threw in the water?

(McDaniel et al., 1995, p.720)

The sentence in (2a) is a ' $w h$-scope marking' construction in which the sentence initial position is marked by an expletive wh-word 'what' and (2b) is a 'wh-copying' construction in which the same wh-word appears both in the matrix and embedded clauses. These types of structures are also known to appear in the L1 acquisition of French (Jakubowicz, 2004, 2011; Jakubowicz \& Strik, 2008; Strik, 2006) and Spanish (Gutierrez, 2004).

Similar alternative constructions for complex wh-questions have also been observed in L2 acquisition of English (e.g., Gutierrez, 2005; Guitierrez \& Mayo, 2008; Wakabayashi \& Okawara, 2003; Yamane, 2003). For example, Gutierrez (2005) and Guitierrez \& Mayo (2008) report that L1 Spanish-Basque bilingual speakers produced the following sentences for the target sentence 'who do you think lived in the house?'

(3) a. *What do you think who lived in that house? (Gutierrez \& Mayo, 2008, p. 277)

b. *Who do you think who lives in the house? (Gutierrez, 2005, p.174)

The sentence in (3a) is a wh-scope marking construction and (3b) is a wh-copying construction. These constructions are not the results of L1 influence because learners' L1s do not allow these constructions. The L1s of the speakers who produced constructions as in (3) include Japanese (Schulz, 2006; Wakabayashi \& Okawara, 2003; Yamane, 2003) and bilingual Spanish/Basque (Gutierrez, 2005; Guitierrez \& Mayo, 2008) which do not license constructions such as in (3). The fact that these constructions appear in the acquisition of both L1 and L2 even though such constructions are not available in language input nor the learners' L1 has raised an important question about what causes the production of the non-target-like structures in the process of language acquisition.

A number of studies in L1 and L2 acquisition have proposed that learners' use of those non-target-like structures is a developmental phenomenon that occurs when learners try to overcome the high derivational complexity of long-distance wh-movement. As long-distance wh-movement requires movement of wh-element across clausal boundary, learners will need the capacity to deal with the complex long-distance processing. When they do not have this capacity, they develop constructions that are derivationally less complex. Jakubowicz and Strik (2008), for example, claimed that child language acquisition is sensitive to computational complexity of the syntactic derivation, so that children first attempt to avoid long-distance movement of the wh-phrase and often resort to target-deviant productions, 
such as wh-scope marking and wh-copying constructions in (2). Slavkov (2015) suggested that L2 learners also create derivationally simpler alternative forms to compensate for their lack of competence to carry out long-distance wh-movement during the developmental process.

The present study aims to investigate Korean EFL learners' interlanguage in the development of English long-distance wh-movement. It will examine the bi-clausal $w$-question interlanguage forms produced by Korean EFL learners and see how those forms change as the learner's English proficiency increases. Specifically, this study will ask if the change can be explained by the 'derivational theory of complexity' which claims that degree of derivational complexity is related to the language developmental process. The concrete research questions of this study will be presented after a brief introduction to the derivational theory of complexity and a review of previous work related to the theory.

\section{BACKGROUND}

\section{A. Wh-questions and Derivational Complexity}

The hypothesis that language develops from derivationally simpler structures (i.e. structures involving less syntactic operations) to more complex ones (i.e., structures involving more syntactic operations) has existed since the 1960 s. Often called the 'derivational theory of complexity', this idea has been tested by a growing number of studies in L1 language acquisition (e.g., Hamann et al., 2007; Jakubowicz, 2011; Jakubowicz and Nash, 2001). These studies generally suggest that constructions involving less complex syntactic derivation appear prior to those involving more complex derivation in the language acquisition process. The most commonly studied forms in those studies are wh-constructions in different languages. For example, French allows four types of mono-clause wh-questions with varying degrees of derivational complexity.

(4) French mono-clause $W h$-questions
a. Tu as vu qui?
'You saw who?'
b. Qui ${ }_{i}$ tu as vu $t_{i}$ ?
'Who you saw?'
c. C'est qui $i_{i}$ [que tu as vu $t_{i}$ ] (clefted- $w h$ )
'Who is it that you saw?'
d. Qui ${ }_{i}$ as $s_{k}$ tu $t_{k}$ vu $t_{i}$
'Who did you see?'
(wh-in-situ)
(wh-fronting without S-V inversion)
(wh-fronting with S-V inversion)

(from Jakubowicz, 2011, p. 341)

Among the above French wh-questions, the wh-in-situ construction (1a) adopts no overt movement of the wh-word while (1b), (1c) and (1d) involve movement of the wh-word from the base-generated position. In terms of derivational complexity, therefore, (1a) is the least complex structure among the four constructions. Several studies in child L1 French acquisition have found that children's early wh-question production is characterized by the high rate of the wh-in-situ constructions like (1a) and almost complete absence of the construction like (1d) which requires subject-verb inversion operation as well as overt wh-movement (Hamann 2000, 2006; Jakubowicz, 2011; Plunkett, 1999).

With regard to the early L1 production of mono-clausal wh-questions, however, target language properties constrain the available options for children's production. Although wh-in-situ construction is derivationally the least complex form, it has been reported that children learning L1 English rarely produce constructions with wh-in-situ, and produced wh-questions with a sentence-initial wh-phrase from the very early stage (Guasti, 2002; Strik, 2008). This rare production of wh-in-situ construction has also been documented L1 acquisition of Dutch (Jakubowicz and Strik, 2008; Van Kampen, 1997) and Portuguese (Soares, 2006). Unlike French, these languages do not license wh-in-situ for normal wh-questions. These findings suggest that although early child L1 acquisition is affected by derivational complexity, it is also constrained by the input to which children are exposed. That is, children prefer derivationally less complex structures, but only when those structures are a legitimate part of adult grammar.

Nonetheless, the subsequent development of more complex wh-questions allows alternative forms that are not licensed in child's L1. As presented earlier in (2), wh-scope-marking constructions and wh-copying constructions, which do not exist in language input available to L1 English learning child, have often been observed in children's production. Interestingly, although prohibited in English, wh-scope marking and wh-copying are cross-linguistically attested options to derive complex wh-questions. The wh-scope marking construction is a legitimate option in Romani (McDaniel, 1989), Hungarian (Horvath, 1997), and German (Felser, 2004). The wh-copying construction is acceptable in Frisian (Hiemstra, 1986), some dialects of Dutch (van Kampen, 1997), and some varieties of colloquial German and Romani (Fanselow \& Mahajan, 2000; McDaniel, 1986). Although wh-scope marking and wh-copying constructions are not allowed in adult English grammar, they are admissible syntactic options in human language which are derivationally less complex than English bi-clausal wh-questions.

It has also been suggested that derivational complexity plays a role in the L2 acquisition process (Prévost, 2006; Prévost et al., 2010; Prévost, Strik, \& Tuller, 2014, Slavkov, 2015). Studies in child L2 French (Prévost, 2006; Prévost et al. 2010, Prevost et al. 2014) found that the French wh-question forms involving fewer movement operations are generally acquired earlier than those involving more movement operations. These studies raised the possibility that 
child L2 learning process is influenced by derivational complexity without discounting the possibility of an interaction between L1 properties and derivational complexity.

Comparatively fewer studies have examined wh-questions in adult L2 acquisition of English. Slavkov (2015) examined English complex wh-questions produced by lower-intermediate level English learners whose L1s are French and Bulgarian. In this study, Slavkov found that both French and Bulgarian learners resorted to a variety of non-target-like constructions with less derivational complexity. Some of these constructions cannot be explained by either L1 influence or L2 input, and Slavkov proposed that adoption of alternative forms is part of the avoidance strategies used as an escape-hatch from the high complexity of English complex wh-questions. The study, however, did not allow us to see how learners in different developmental stages produce different alternative forms, because the proficiency levels of Bulgarian and French learners in the study were all in the low-intermediate range. Kim (2017) compared Korean college and high school EFL learners' productions of English wh-questions. He found that Korean college EFL learners produced greater number of derivationally more complex alternatives to long-distance wh-questions than high school EFL learners did. While this finding is suggestive of the role of derivational complexity in L2 developmental process of long-distance wh-questions, the study did not check on whether the college EFL learners' English proficiencies were indeed higher than those of the high school learners. The present study is the subsequent to Kim (2017), with the aim to find out whether EFL learners with differing English proficiency show different interlanguage productions for complex wh-questions.

\section{B. Syntax of Alternatives for English Bi-clausal Wh-questions}

The degree of derivational complexity is related to the number of grammatical operations involved in the derivation of a sentence. The present study adopts Chomsky's (2001) model of sentence generation in which derivation occurs through the process of External Merge and Internal Merge (or movement) operations. In English wh-question derivation, the wh-word is first externally merged to establish the base structure (wh-in-situ construction) and then undergoes Internal Merge to the left periphery of the clause. Therefore, wh-questions without Internal Merge of the wh-word (i.e., wh-in-situ construction; e.g., 'Do you eat what?') is derivationally less complex than the ones with Internal Merge (wh-construction with overt wh-movement; e.g., 'What do you eat?').

When it comes to the bi-clausal wh-questions, several potential alternative forms could be predicted to be produced by L2 learners.

Wh-copying construction: The use of the wh-copying (examples were given in (2b) and (3b)) has been reported in L1 acquisition of a variety of languages and in some of the L2 acquisition studies (Bruening, 2006; Jakubowicz, 2011). It is generally accepted that long-distance cyclic wh-movement (or Internal Merge) has been instantiated in this construction, but without deleting the wh-copy located in the Spec-CP of the second clause (Fanselow and Mahjan, 2000; Felser, 2004). (5) illustrates the simplified structure of wh-copying construction in (2b) .

$(5) *\left[\mathrm{CP}_{\mathrm{Cho}}\right.$ do you think [ $\mathrm{CP} \mathrm{Who}_{i}$ Gumby threw $t_{i}$ in the water $\left.]\right]$ ?

Production of the wh-copying construction indicates that the learner fails to delete the phonological feature of the wh-copy in the embedded Spec-CP once the wh-phrase has moved to Spec-CP of the main clause ${ }^{1}$. In this sense, the degree of derivational complexity of the wh-copying construction is a little lower than the grammatical bi-clausal wh-construction which has employed 'deletion' operation along with the Internal Merge operations.

Wh-scope marking construction: For wh-scope marking constructions (such as *What do you think who Bert kissed?), two different analyses have been suggested. In the first analysis, which is often called the direct dependency approach, the wh-word moves partially to Spec-CP of the embedded clause from its base position, and the scope-marker "what' is added to the sentence initial position. This scope marker could be a vacuous expletive (among others, see McDaniel, 1989; Sabel, 2000) or a separated and raised wh-feature pronounced as default wh-word 'what' (Cheng, 2000, Hiemstra, 1986). Regardless of whether it is an expletive or a raised $w h$-feature, there is a direct dependency between the scope marker and the sentence medial wh-word. In the second analysis, which is called the indirect dependency approach, the construction is analyzed as having two independent and separate local wh-movements. For example, the sentence $*_{w h a t}$ do you think who Bert kissed? is the result of two short wh-movements as illustrated in (6).

(6) *What ${ }_{i}$ do you think $t_{i}$ ? who $_{j}$ Bert kissed $t_{j}$ ?

In this analysis, two questions are connected, but no chain relation is established between the two wh-phrases in the construction. (see Dayal, 2000; Horvath, 2000).

According to the direct dependency approach, the derivational complexity of $w h$-scope marking is difficult to judge as it employed one short $w h$-movement (one Internal Merge) and an addition of $w h$-word 'what' to the structure. While it is obvious that short wh-movement is derivationally less complex than the long-distance wh-movement, previous literature has not weighed the cost of externally merging an expletive to the structure in comparison to the cost of Internal Merge. When the indirect approach is assumed, wh-scope marking is derivationally simpler than cyclic long-distance wh-movement as it adopts only a short movement for each independent clause (thus, two unconnected short movements). The same view on the complexity of wh-scope marking construction was taken in Slavkov (2015).

\footnotetext{
1 According to Chomsky (2005), the minimization of computation requires deletion of all but one copy at the PF.
} 
Silent scope marking construction: Constructions like (7), which is called the silent scope marking construction, were reported to appear in previous research on L2 acquisition of English complex wh-movement (Slavkov, 2015).

(7) *Do you think who Mary sent to buy eggs? (for "Who do you think Mary sent to buy eggs?")

(Slavkov, 2015, p.199)

In this construction, the $w h$-phrase has risen to Spec-CP of embedded clause, but, is stranded there, failing to move further to Spec-CP of the main clause (thus, one short $w$-movement). Therefore, this construction is believed to be derivationally less complex than long-distance $w h$-movement, wh-copying, and $w h$-scope marking constructions (also see Slavkov, 2015).

Wh-Scope marking with wh-in-situ construction: Another potential alternative to the long-distance wh-movement construction is a construction in which the wh-phrase remains in-situ, but the sentence initial position is scope-marked by a wh-word what, as shown in (8).

(8) What do you think Jane ate the cookies where?

Although no specific syntactic analysis has been proposed for this structure in literature, it is reasonable to assume that it has the lower derivational complexity than the normal wh-scope marking construction as no wh-movement has been made even within the embedded clause in this construction.

To summarize, in long-distance (LD) wh-movement, cyclic wh-movement and a deletion operation are both employed, whereas in the wh-copying construction, cyclic long-distance $w h$-movement is employed without the deletion operation. In the $w h$-scope marking construction, either one short $w h$-movement and an external merge of what are employed (according to the direct dependency approach) or two independent short movements are employed (according to the indirect dependency approach). In the silent scope marking construction, only one short local wh-movement is employed. Finally, in the wh-scope marking with wh-in-situ construction, only an external merge of the scope marking is made, without wh-movement of any sort.

\section{Korean Wh-questions}

Unlike English and French, Korean language does not employ overt wh-movement (Bach, 1971; Huang, 1982). Consider the Korean sentences in (9).

(9) a. Sunhi-ka cha-eyse khephi -lul masi-ess-eyo.

Sunhi-Nom car-in coffee-Acc drink-Pst-End

'Sunhi drank coffee in the car'

b. Sunhi-ka edise khephi-lul masi-ess-eyo ?

Sunhi-Nom where coffee-Acc drink-Pst-End

'Where did Sunhi drink coffee?'

c. [ [Sunhi-ka edise khephi -lul masi-ess -tago] sayngkakha-yyo]]?

Sunhi-Nom where coffee-Acc drink-Pst-Comp think-End

'Where do (you) think Sunhi drank coffee?'

Note: Nom-nominative Case marker, Acc-accusative Case marker, Pst-past tense morpheme, End-ending morpheme, Comp-complementizer

Sentence (9a) shows the typical word order in Korean in which the adjunct cha-eyse (in the car) and object khephi-lul (coffee) come before the verb. When a part of sentence is unknown and needs to be asked, the unknown part is replaced by a $w$-word in Korean. In (9b), the unknown part is the adjunct indicating a place and the wh-word edise (where) has been base-generated in the adjunct position, and stayed in-situ. Example (9c) is a Korean bi-clausal wh-question equivalent to 'Where do you think Sunhi drank coffee?' Because Korean is a head final language, the main verb comes after the embedded object clause. In (9c), the main verb sayngkakha 'think' comes after the embedded clause while main subject ne 'you' is dropped (as Korean is a pro-drop language). With respect to the formation of wh-questions, Korean contrasts with English in two respects. First, there is no overt wh-movement in Korean, and second, Korean clause order is the opposite to English.

Considering that the Korean wh-word stays in-situ, the wh-Scope marking with wh-in-situ construction shown in (8) is a possible interlanguage structure if Korean learners transfer their L1 syntax, while still implementing wh-scope marking. The sentence in (8), therefore, may be interpreted in two different ways: 1) learners' use of a derivationally less complex alternative form or 2) learners' transfer of the L1 syntactic feature responsible for (non) wh-movement.

\section{THE STUDY}

\section{A. Research Questions}

The present study specifically asks the following two questions. First, what are the alternatives to English bi-clausal wh-questions produced in the interlanguage of adult Korean EFL learners? Second, does derivational complexity play a role in the development of those alternative forms? That is, can the change in interlanguage forms be accounted for by the hierarchy of derivational complexity?

\section{B. Methods}

1. Participants 
Participants in this study were 107 adult Korean speakers learning English in Korea. They were either undergraduate students $(\mathrm{N}=103)$ or graduate students $(\mathrm{N}=4)$ in various areas of study including English language and literature, business administration, engineering, and natural science at a university in South Korea. Participants ages ranged from 18 to 40. Because official English education in South Korea begins in the $3^{\text {rd }}$ grade, all of the participants studied English at least 10 years in elementary and secondary schools before entering college. In addition, participants were either taking or had completed the university's general English courses, which are required for all students as part of general education requirements.

Participants were divided into three proficiency groups based on their TOEIC (Test of English for International Communication) scores: a HIGH group ( $\mathrm{N}=38)$, an INTERMEDIATE Group ( $\mathrm{N}=34)$, and a LOW Group ( $\mathrm{N}=35)$. All students at the university are required to take the TOEIC as a requirement for graduation, and the participants in this study were chosen from those who had already taken the exam. ${ }^{2}$ Students who had resided in an English-speaking country for more than one year were excluded from participation.

2. Materials and Procedure

In order to elicit complex wh-questions from the L2 learners, a written-elicitation task was used. A total of 12 test items were employed in the task, with each item containing a description providing a context and a task instruction. For example, for the target wh-question "Where do you think Brian met Jane yesterday?," the test item included the context description and task instruction as follows: Context Description, You know that Brian met Jane yesterday, but you don't know where they met. Now you want to know where your friend thinks Brian met Jane yesterday; Task, Write a question in English to ask your friend where he/she thinks Brian met Jane yesterday. (think, Brian, meet, where).

The context description and task instruction were given in Korean, and students were asked to include all the words given in parentheses in their questions with possible verb conjugations. The structure of the target wh-questions used in the present study was same as the ones used in Slavkov (2015)'s study: six questions with wh-words moved from the object position (e.g., who do you think James is kissing?) and six from the adjunct position (e.g., Where do you think David is sleeping?). The verbs used in the embedded clause include meet, be, sleep, have, put, choose, send, ask, call, kiss, and talk. The main verb for all target questions was think.

The written-elicitation task was given to participants in groups, and no time limit was set for the completion of the task. Participants' background information (including age, years of English study, and TOEIC score) was gathered through a background questionnaire distributed after the written-elicitation task was completed.

\section{RESULTS AND DiSCUSSION}

Our participants produced a total of 1284 questions. The questions were classified into the following structure types: LD wh-movement, wh-copying, wh-scope marking, silent scope marking, scope marking with wh-in-situ, L1 clause order, and wh-about-wh types. Among those, LD wh-movement, wh-scope marking, and silent scope marking types were the three most common production types. Together, these three types account for approximately $75 \%$ of all productions. Table 1 presents the types and production rates of $w h$-questions produced by the Korean learners.

TABLE 1

STRUCTURE TYPES OF ELICITED-WRITTEN $W H$-QUESTIONS BY KOREAN LEARNERS

\begin{tabular}{lc}
\hline Structure Type & $\%$ Production $($ No. of sentences) \\
\hline LD $w h$-movement Type & $29.4 \%(378)$ \\
Wh-copying Type & $0.2 \%(2)$ \\
Wh-Scope marking Type & $29.7 \%(382)$ \\
Silent scope marking Type & $15.7 \%(201)$ \\
Wh-Scope marking with $w h$-in-situ Type & $1.7 \%(22)$ \\
Wh-about- $w h$ Type & $8.4 \%(108)$ \\
L1 clause order Type & $7.4 \%(95)$ \\
Others & $7.5 \%(96)$ \\
Total & $100 \%(1284)$ \\
\hline
\end{tabular}

Korean learners produced a fairly large number of constructions containing long-distance (LD) wh-movement (29.4\% of all productions). Examples are given in (10).

(10) LD wh-movement Type

a. Where do you think David is sleeping?

(Targeted) (H-16)

b. Who do you think Jane is talking to?

(Targeted) (H-18)

c. Where do you think Brian met Jane?

(Targeted)

d. Who do you think John talk to?

(Non-targeted)

\footnotetext{
${ }^{2}$ Students were assigned to the HIGH group if their TOEIC score is 870 or above, the INTERMEDIATE group if between 650-869, and LOW group if below 649. These TOEIC scores were set arbitrarily to assign an approximately balanced number of subjects across groups, and thus, the terms 'HIGH', INTERMEDIATE' and 'LOW' in this article do not represent the standardized proficiency levels.
} 
H: HIGH group learner, I: INTERMEDIATE group learner, L: LOW group learner

Some non-targeted productions such as (10d) were not grammatically correct, but these sentences were still considered to have the same degree of complexity as the targeted LD wh-questions in terms of $w h$-derivation.

As for the wh-copying type constructions, our participants produced only two sentences of this type, suggesting that Korean learners rarely use $w h$-copying strategy as an alternative to long-distance $w h$-movement. The two sentences produced are given below.

(11) Wh-copying Type

a. Who do you think who was sent by Jessica for buying milk? (H-18)

b. Who do you think who Mary is calling?

A considerable number of $w h$-scope marking constructions were produced. A total of 382 sentences $(29.7 \%$ of all productions) were of this type. (12) shows some example sentences.

(12) Wh-scope marking construction Type

a. What do you think where Tom put the book? $\quad(\mathrm{H}-20)$

b. What do you think where is Elisa? $\quad(\mathrm{H}-21)$

c. What do you think whom Ben chose as a partner? (H-19)

d. What do you think where David sleep?

e. What do you think who did Jessica send to buy? (I-5)

f. What do you think who Jane talk to? (L-21)

g. What do you think where is David sleeping? (L-4)

Although all $w h$-scope marking constructions in our data were identical in the use of scope marker 'what' followed by the 'do you think' clause, the structure of the embedded clause exhibited two distinctive patterns: ones without subject-auxiliary (Sub-Aux) inversion and ones with such inversion. In (12a), (12c), (12d), and (12f), no Sub-Aux inversion was employed in the embedded clause whereas (12b), (12e), and (12g) show Sub-Aux inversion. In total, our data showed 198 (15.4\% of total production) scope marking constructions without Sub-Aux inversion and 184 (14.3\% of total production) constructions with Sub-Aux inversion. This distinction may be meaningful in that the constructions with Sub-Aux inversion could be seen as employing two separate short movements as shown in (13), which might correspond to the analysis of $w h$-scope marking construction made in the indirect dependency approach.

(13) What ${ }_{i}$ do you think $t_{i} \ldots$ where ${ }_{j}$ is David sleeping $t_{j}$ ? (Analysis of (12g))

The possibility of this analysis for wh-scope marking constructions with Sub-Aux inversion was also suggested in Slavkov (2015). While further studies are needed to decide whether $w h$-scope marking constructions without Sub-Aux inversion (such as (12a), (12c), (12d), and (12f)) are better explained by the direct dependency approach, it seems relatively reasonable to assume that cope marking constructions with Sub-Aux inversion (such as (12b), (12e), and $(12 \mathrm{~g}))$ fit better with the analysis provided by the indirect dependency approach. This is because the two $w h$-movements in the construction are independent and no chain relation exists between the two wh-words. Following this assumption, the subsequent analysis of results by proficiency group will pay particular attention to how the production rates of $w h$-scope marking constructions with Sub-Aux inversion change as learners' proficiencies increase.

Another important type of alternative forms produced by our participants is the silent scope marking constructions that contain only one local wh-movement. A total of 201 sentences (15.7\% of total production) were of this type. Examples were given in (14).

(14) Silent scope marking Type

a. Do you think where Mary have dinner yesterday? (I-5)

b. Do you think who Jessica sends to buy? (I-23)

c. Do you think where Tom put book? (L-3)

d. Do you think who is kiss with James? (L-17)

e. You think where is Jane's car? (L-28)

These sentences were all bi-clausal sentences with a sentence medial wh-word, which were also common in Slavkov's (2015) and Wakabayashi \& Okawara's (2003) L2 English studies. Sentences like (14e), which is bi-clausal, but with declarative formation, were also included in this type.

Wh-scope marking with wh-in-situ type sentences were also produced, but their numbers were very small (22 sentences, $1.7 \%$ of all production). The following sentences are some of the $W h$-scope marking constructions with wh-in-situ in our L2 data.

(15) Wh-scope marking with wh-in-situ Type

a. What do you think Jane is talking to whom?

b. What do you think Sofia ask who bring the apple?

c. What do you think Ben chose who as a partner?

d. What are you think Jessica send who buy the milk? (L-16)

In addition to the alternative types presented so far, our participants unexpectedly produced a considerable number of sentences that include about that connects the two wh-clauses, which I will name $W h$-about-wh Type (a total of 108 sentences, $8.4 \%$ of total production). 
(16) Wh-about-wh Type
a. What do you think about where Brain met a person?
b. How you think about where Tom is put book?
c. What do you think about whom Mary call?
d. What do you think about where is David sleep?
e. What do you think about who is she?

Sentences in (16) are different from normal $w h$-scope marking constructions in that the second wh-clause (e.g., where Brian met a person in (16a)) is the complement of the preposition 'about,' and that the overall structure of this type is

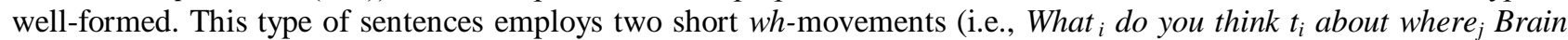
met a person $t_{j}$ ?), and thus, its degree of derivational complexity is considered lower than long-distance wh-movement Type.

Another unexpected type of production that occurred was the L1 Korean clause order type in which the main subject and verb "you think" are located after the embedded clause.

(17) L1 clause order Type
a. Who does James kiss do you think?
b. Who Ben chose as a partner do you think?
c. Who ask Sofia bring apple do you think?
d. Where David sleep do you think?
e. Where is Jane's car you think?
f. Where is Mary have dinner think?

A total of 95 sentences $(7.4 \%)$ were in this type. Obviously this construction follows the Korean clause order in which the main clause verb follows the embedded clause. While there is a short local wh-movement in the embedded clause, the learners added the main clause (do you think, you think, think) after the embedded clause. With regard to this construction, I propose that the learners' strategy of adopting the L1 clause order would enable them to avoid the difficult task of making complex wh-movement. That is, by resorting to the Korean macro-structure which puts the embedded clause before the main clause, the learners tried to express what they wanted with the employment of only one local wh-movement, as illustrated in the analysis in (18).

(18) Analysis of L1 clause order Type

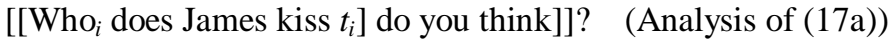

The 'others' category includes productions that are not bi-clausal, that are clearly isolated and idiosyncratic, or that are difficult to understand meaning due to global errors. For example, sentences such as 'Who James kiss?' and 'What's think buy?' were classified into this category.

One of our research aims was to examine how alternative structures vary across the three proficiency groups and whether this variation can be explained in terms of complexity hierarchy. If derivational complexity is a factor constraining the production of bi-clausal wh-questions, L2 interlanguage would exhibit an increasing number of derivationally more complex alternatives as learners' proficiencies increase. Figure 1 shows production rates of different alternative types by the three proficiency groups in our study. Wh-copying type was excluded in the group analysis because only two sentences in type were produced (one by the HIGH and the other by INTERMEDIATE group) and, thus, it could not be considered as a genuine interlanguage form used by Korean learners of English.

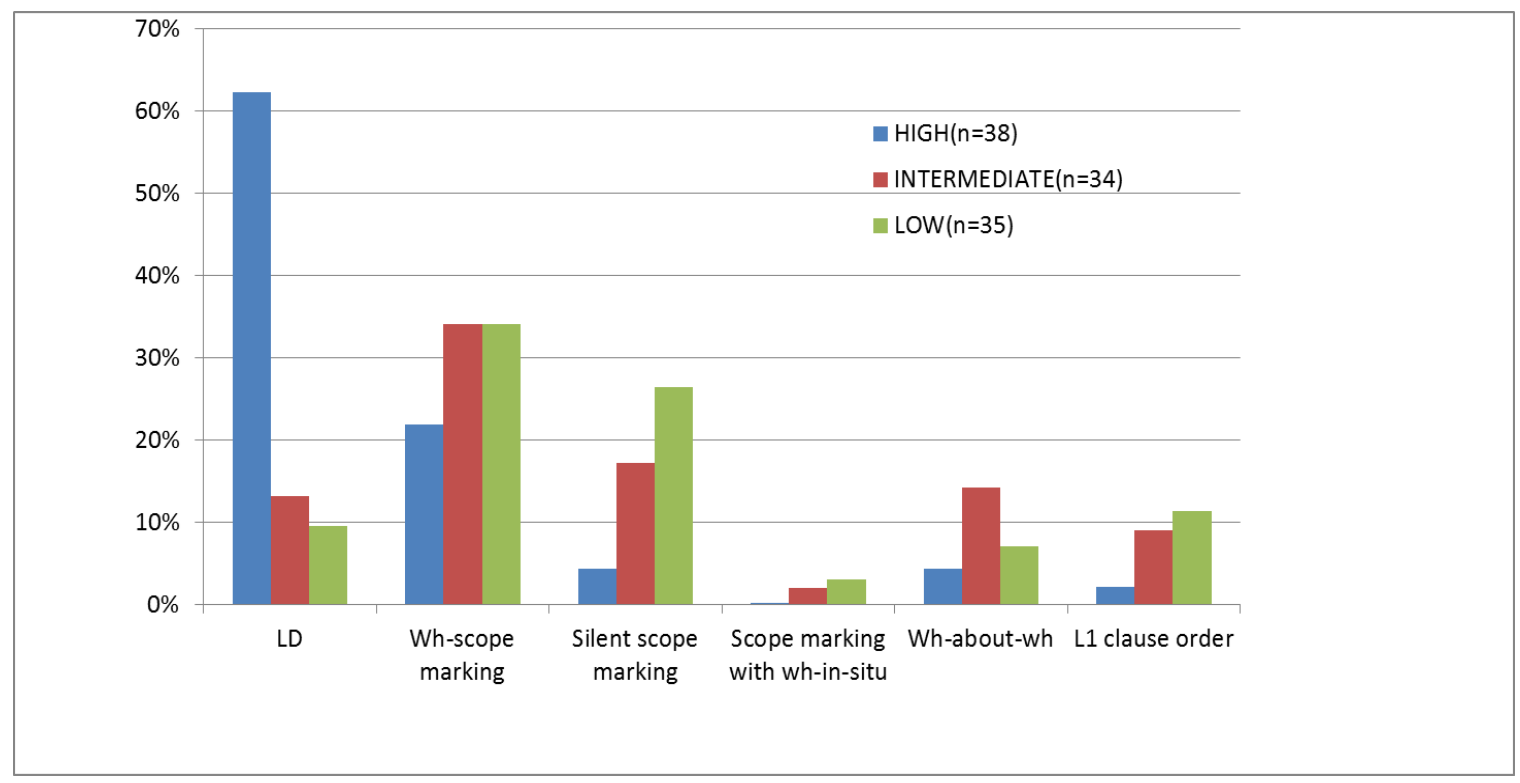

Figure 1. Production rates of alternative types by proficiency group 
For the LD type, the HIGH group produced this type at a distinctively higher rate $(62.3 \%$ of the group's total production) compared to the two other groups (INTERMEDIATE group, 13.2\% of the group's total production; LOW group, 9.5\% of the group's total production). For the silent scope marking type, on the other hand, the LOW group showed highest production rate $(26.4 \%)$, followed by the INTERMEDIATE group (17.2\%) and the HIGH group (4.4.\%). For the scope making with wh-in-situ type, the LOW group showed a higher (3.1\%) rate than the INTERMEDIATE group $(2.0 \%)$ and the HIGH group $(0.2 \%)$, although the low production rate of this type $(1.7 \%$ of total production) made the validity of this type's distinction somewhat weak. Overall, these results generally conform to the prediction made by the derivational theory of complexity in that less proficient L2 learners relied more on derivationally less complex alternative forms when facing the task of constructing complex wh-questions.

A large number of wh-scope marking constructions were produced by all three groups. In total, the HIGH group learners produced 100 sentences $(21.9 \%)$, the INTERMEDIATE learners produced 139 sentences $(34.1 \%)$, and the LOW learners produced 143 sentences of this type (34.1\%). This was the second most common production type in the HIGH group (following the LD type), and the most common production type in the INTERMEDIATE and LOW groups. The fact that the HIGH group learners' production rate of this type is placed between the LD type (62.3\%) and the silent scope marking type (4.4.\%) suggests that the interlanguage stage characterized by the wh-scope marking production is an intermediate stage that occurs between the LD wh-movement stage and the one short wh-movement stage. Both the INTERMEDIATE and LOW group learners, then, mainly belong to this intermediate stage in that the wh-scope marking construction is the most common type of their production. These results are also consistent with the prediction made by the derivational theory of complexity, as the order of the interlanguage stages conforms to the order of derivational complexity.

When wh-scope marking sentences were further divided into subtypes according to whether or not Sub-Aux inversion is employed in the embedded clause, the three groups showed notable differences. Figure 2 shows the rates of two subtypes of wh-scope marking constructions by the proficiency groups.

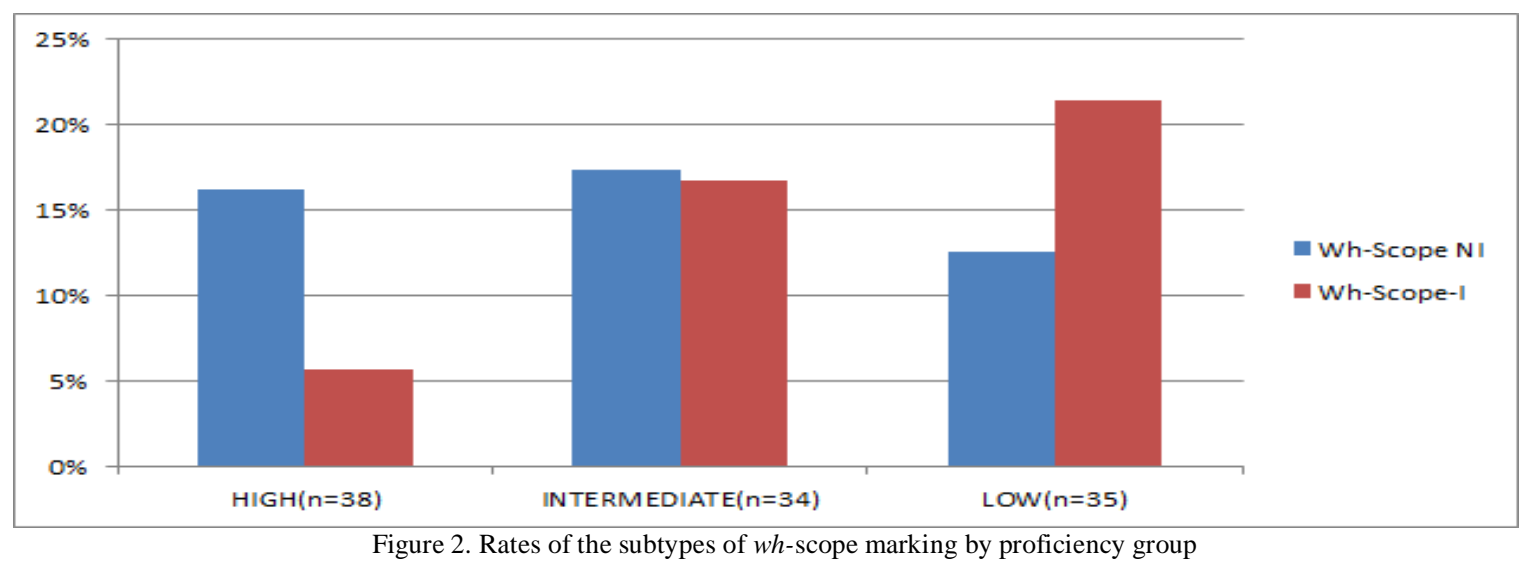

Between the two subtypes, the High group produced the Wh-Scope marking-Non Inversion subtype (Wh-scope-NI) much more frequently than the wh-Scope marking-Inversion subtype (Wh-scope-I) (16.2\% vs. 5.7\%). Conversely, the LOW group produced the $w$ h-scope-NI type considerably less than the wh-scope-I type (12.6\% vs. $21.4 \%)$. In fact, the production rate of the Wh-scope-I type dropped as the learners' proficiency increases $(21.4 \%$ (LOW) vs. $16.7 \%$ (INTERMEDIATE) vs. 5.7\% (HIGH)). As discussed earlier in this section, the wh-scope marking with Sub-Aux inversion subtype may be better accounted for by the indirect dependency approach which assumes two separate employments of short wh-movement. The present result suggests that the $w h$-scope-NI type (which might assume the direct dependency between the scope marker and the sentence medial wh-word) is more difficult to produce than the Wh-scope-I type (which may assume two independent short wh-movements). This finding, in turn, tells us that, although both the INTERMEDIATE and LOW groups produced $w h$-scope marking construction at the same rate (34.1\%), the LOW group learners depended more on the easier subtype (Wh-scope-I type) of this construction.

As for the Wh-about-wh type, an interesting result was found. As this type of sentences utilize two short wh-movements, it must be considered to have a lower degree of derivational complexity than the LD type construction, but a higher complexity than the silent scope marking type construction. Our data showed that the INTERMEDIATE group produced this type more frequently than any other groups (58 sentences, 14.2\%), followed by LOW Group (30 sentences, $7.1 \%$ ) and HIGH Group (20 sentences, 4.4.\%). This result was different from that of the LD type constructions (whose number consistently increased as the learners' proficiency increased) and from the silent scope marking type constructions (whose number consistently decreased as the learners' proficiency increased). While I do not intend to provide a definitive answer as to what caused the INTERMEDIATE learners to produce this type more than the other groups, I tentatively propose that the Wh-about-wh type constructions work as one of the intermediate constructions bridging the gap between the one short wh-movement stage and the LD wh-movement stage. Given that the $W h$-about-wh type construction is derivationally less complex, but grammatically still legitimate alternative to the 
LD movement type, this type could be a good option for the learners who have reached the proficiency level well enough to know the ungrammaticality of silent scope marking construction, but have not reached the proficiency level to carry out complex wh-movement. Further investigation of this particular type of construction will be needed, of course, especially regarding its hierarchical relationship with the wh-scope marking construction in terms of derivational complexity. I will leave this for future research.

The L1 clause order type was produced by all three groups. The LOW group produced them at highest rate (48 sentences, 11.4\%), followed by the INTERMEDIATE group (37 sentences, 9.1\%) and the HIGH group (10 sentences, $2.2 \%)$. Although this result was consistent with the general expectation that the lower level L2 learners are more likely to be influenced by the L1 structure than higher level learners, it also showed that the transfer effect remained strong even for some INTERMEDIATE and HIGH proficiency learners. This result seems to suggest that processing complex wh-questions is a difficult task even for some higher-level learners, leading them to resort to their L1 clause order, which allowed them to utilize just one short wh-movement.

\section{CONCLUSION}

Korean EFL learners produced a variety of alternative structures to English bi-clausal wh-questions, including wh-scope marking, silent scope marking, and wh-scope marking with wh-in-situ, L1 clause order transfer, and Wh-about-wh types. The appearance of these alternatives indicates that Korean learners have relied on derivationally less complex interlanguage forms in order to compensate for their lack of L2 competence to execute the highly complex derivational process needed to form bi-clausal wh-questions.

This study generally supported the derivational theory of complexity, although further work is needed to examine the validity of some of the assumptions made in this study. In general, more proficient L2 learners produced greater number of LD wh-movement structures while less proficient learners produced larger number of structures that are derivationally less complex, such as silent scope marking construction and scope marking with wh-in-situ construction. The general interlanguage order of the three most common production types in our data (silent scope marking type $\rightarrow$ $w h$-scope marking type $\rightarrow$ LD $w h$-movement type) is consistent with the order of degree of derivational complexity.

The current study also found two somewhat unexpected interlanguage constructions: the wh-about-wh type and the L1 clause order type. The $w h$-about-wh type, which employs two short wh-movements, is considered to occur in the period between one short $w h$-movement stage and LD $w h$-movement stage. The L1 clause order type may be seen as the learners' resort to their L1 macro-structure in an attempt to avoid LD wh-movement. In terms of the derivational complexity hierarchy, the L1 clause order type, which takes one short wh-movement, may be placed lower than the wh-about-wh type. In this sense, the fact that the L1 clause order type is produced largely by the LOW group while the $w h$-about-wh type is produced largely by the INTERMEDIATE group is also consistent with the derivational theory of complexity.

The empirical data obtained in the present study suggest that derivational complexity plays a role in developmental process of Korean EFL learners' acquisition of bi-clausal wh-questions. While the present study focused on the wh-questions produced by Korean EFL learners, it would be worthwhile for future studies to test the role of derivational complexity with other target structures, L1s, and learning contexts.

\section{ACKNOWLEDGMENTS}

The present work was supported by the 2014 Research Grant of Incheon National University. I thank Professor Rusty Barrett at the University of Kentucky for comments and feedback on the earlier manuscript of this paper.

\section{REFERENCES}

[1] Bach, E. (1971). Questions. Linguistic Inquiry 2, 153-166.

[2] Bruening, B. (2006). Differences between the wh-scope marking and wh-copy constructions in Passamaquoddy. Linguistic Inquiry 37, 25-49.

[3] Cheng, L. (2000). Moving just the feature. In U. Luts, G. Muller \& A. von Stechow (eds.), Wh-scope marking. Amsterdam: John, Benjamins, 77-99.

[4] Chomsky, N. (2001). Derivation by phase. In M. Kenstowicz (ed.), Ken, Hale, a life in language. Cambridge, MA: MIT Press, $1-52$.

[5] Chomsky, N. (2005). Three factors in language design. Linguistic Inquire 36, 1-22.

[6] Dayal, V. (2000). Scope marking: Cross-linguistic variation in indirect dependency. In U. Luts, G. Muller, \& A. von Stechow (eds.), Wh-scope marking. Amsterdam: John, Benjamins, 157-193.

[7] Fanselow, G. \& A. Mahajan. (2000). Towards a minimalist theory of wh-expletives, wh-copying and successive cyclicity. In U. Luts, G. Muller, \& A. von Stechow (eds), Wh-scope marking. Amsterdam: John Benjamins, 195-230.

[8] Felser, C. (2004). Wh-copying, phrases, and successive cyclicity. Lingua 114, 543-574.

[9] Guasti, M. T. (2002). Language acquisition: The growth of grammar. Cambridge, MA: MIT Press.

[10] Gutierrez, M. J. (2004). Non-adult questions in the acquisition of L1 Spanish long-distance wh-questions: A longitudinal investigation. Paper presented at The Romance turn workshop on the acquisition of Romance Languages, Madrid. 
[11] Gutierrez, M. J. (2005). The acquisition of English LD wh-questions by Basque/Spanish bilingual subjects in a school context. Unpublished $\mathrm{PhD}$ thesis, University of the Basque Country, Spain.

[12] Gutierrez, M. J. \& M. Mayo. (2008). Non-adult long-distance wh-questions in the non-native acquisition of English. In C. Vidal, M Juan-Garau, \& A. Gaya (eds.), A portrait of the young in the new multilingual Spain. Multilingual Matters Ltd, 264-288.

[13] Hamann, C. (2000). The acquisition of constituent questions and the requirements of interpretation. In M. Friedemann, \& L. Rizzi (eds.), The acquisition of syntax: Studies in comparative developmental linguistics. London: Longman, 170-201.

[14] Hamann, C. (2006). Speculations about early syntax: The production of wh-questions by normally developing French children and French children with SLI. The Catalan Journal of Linguistics 5, 143-189.

[15] Hiemstra, I. (1986). Some aspects of wh-questions in Frisian. North-Western European Language Evolution 8, 98-110.

[16] Horvath, J. (1997). The status of "Wh-expletives" and the partial wh-movement construction of Hungarian. Natural Language and Linguistic Theory 15, 509-572.

[17] Horvath, J. (2000). On the syntax of ' wh-scope marker' constructions: Some comparative evidence. In U. Luts, G. Muller, \& A. von Stechow (eds.), Wh-scope marking. Amsterdam: John Benjamins, 271-316.

[18] Huang, J. (1982). Logical relations in Chinese and the theory of grammar. Unpublished doctoral dissertation, MIT.

[19] Jakubowicz, C. (2004). Is movement costly? Paper presented at The JEL conference (Journeed' Etudes Linguistiques), Nantes.

[20] Jakubowicz, C. (2011). Measuring derivational complexity: New evidence from typically developing and SLI learners of L1 French. Lingua 121, 339-351.

[21] Jakubowicz, C. \& N. Strik. (2008). Scope-marking strategies in the acquisition of long distance wh-questions in French and Dutch. Language and Speech 51, 101-132.

[22] Kim, J.-T. (2017). Alternatives to long-distance wh-movement in L2 English by Korean learners. Korean Journal of Applied Linguistics 33.4, 103-126.

[23] McDaniel, D. (1989). Partial and multiple wh-movement. Natural Language and Linguistic Theory 7, 565-604.

[24] Plunkett, B. (1999). Targeting complex structure in French questions. In A. Greenhill, H. Littlefield, \& C. Tano (eds.), Proceedings of the 23rd Annual Boston University Conference on Language Development (BUCLD). Somerville, MA: Cascadilla Press, 764-775.

[25] Prevost, P. (2006). The phenomenon of object omission in child L2 French. Bilingualism: Language and Cognition 9, $263-280$.

[26] Prevost, P., L. Tuller, M. Scheidnes, S. Ferre \& M. Haiden. (2010). Computational complexity effects in the acquisition of wh-questions in child L2 French. In L. Dominguez, \& P. Guijarres-Fuentes (eds.), New directions in language acquisition: Romance languages in the generative perspective. Cambridge: Cambridge Scholar Publisher, 415-443.

[27] Prevost, P., N. Strik \& L. Tuller. (2014). Wh-questions in child L2 French: Derivational complexity and its interactions with L1 properties, length of exposure, age of exposure, and the input. Second Language Research 30.2, 225-250.

[28] Sabel, J. (2000). Partial wh-movement and the typology of wh-questions. In U. Luts, G. Muller, \& A. von Stechow (eds), Wh-scope marking. Amsterdam: John, Benjamins, 409-446.

[29] Schulz, B. (2006). Wh-scope marking in English interlanguage grammars: Transfer and processing effects on the second language acquisition of complex wh-questions. Unpublished PhD thesis, University of Hawaii, HI.

[30] Slavkov, N. (2015). Long-distance wh-movement and long-distance wh-movement avoidance in L2 English: Evidence from French and Bulgarian speakers. Second Language Research 31.2, 179-210.

[31] Soares, C. (2006). The syntax of the left periphery in European Portuguese and its acquisition. Unpublished doctoral dissertation. Universite Paris \& Saint Denis, France.

[32] Strik, N. (2006). L'acquisition des phrases interrogatives chez les enfants francophones. Psychologie Francaise 52, 27-39.

[33] Strik, N. (2008). The acquisition of interrogative sentences in French and Dutch: A contrastive study. Unpublished doctoral dissertation, Universite Paris \& Saint Denis, France.

[34] Van Kampen, J. (1997). First steps in wh-movement. Wageningen: Ponsen and Looijen.

[35] Wakabayashi, S. \& I. Okawara. (2003). Japanese learners' errors on long distance wh-questions. In S. Wakabayashi (ed.), Generative approaches to the acquisition of English by native speakers of Japanese. Berlin: Mouton, 215-246.

[36] Yamane, M. (2003). On interaction of first language transfer and universal grammar in adult second language acquisition: Wh-movement in L1-Japanese/L2-English interlanguage. Unpublished doctoral dissertation, University of Connecticut.

Jung-Tae Kim, PhD, was born in South Korea, received his B.A. from Korea University, and his Ph.D. from the University of Texas at Austin, USA. He had taught at Washington University in St. Louis, USA until he returned to Korea. He is currently a professor at Incheon National University, South Korea. His research interests include L2 grammar acquisition and L2 learning contexts. 